\title{
MODERNOS Y NEANDERTALES EN LA TRANSICIÓN DEL PALEOLÍTICO MEDIO AL SUPERIOR EN EUROPA*
}

\section{Moderns and Neandertals in the Transition from the Middle to the Upper Palaeolithic in Europe*}

\author{
João Zilhão**
}

Recibido el 17 de abril de 2008. Aceptado el 20 de mayo de 2008

Resumen. El punto de vista de la Revolución Humana ha dominado la Paleoantropología durante la mayor parte de los últimos veinte años. Los recientes avances realizados en campos, como la genética, la antropología física y la arqueología, sin embargo, han desafiado sus principios básicos. Específicamente, ahora se sabe que el Paelolítico superior inicial de Europa fue el producto de poblaciones neardentales y precedió perceptiblemente a la inmigración de seres humanos anatómicamente modernos. Algunos tecnocomplejos como el Bohuniciense, el Uluzziense o el Chatelperroniense, por lo tanto, representan una adquisición independiente de la modernidad de comportamiento por parte de los neardentales. Un corolario a esta conclusión es que, en la época del contacto, estas dos poblaciones humanas de comportamiento y cognición equivalentes deben de haber intercambiado genes y cultura de forma muy significativa. Así lo sugieren los hallazgos fósiles (Lagar Velho y Oase), por una parte, y, por otra, la presencia de innovaciones neardentales (ornamentos personales hechos con dientes de animales) en el repertorio cultural de las primeras sociedades de humanos anatómicamente modernos de Europa.

Palabras clave: Neardental, Hombre moderno, Paleolítico medio y Paleolítico superior.

Abstract. The "Human Revolution" view of modern human origins has dominated Palaeoanthropology for the better part of the last 20 years. Recent developments, in the fields of genetics, physical anthropology and archaeology, however, have challenged its basic tenets. Specifically, the earliest Upper Palaeolithic of Europe is now known to have been the work of Neandertal peoples and to significantly predate the immigration of modern humans. Techncomplexes such as the Bohunician, the Uluzzian or the Châtelperronian, therefore, stand for the Neanderthals' own independent acquisition of behavioural modernity. A corollary of this conclusion is that one should expect significant admixture to have occurred at the time of contact between these two behaviourally and cognitively equivalent human populations, as indeed suggested by fossil finds (Lagar Velho and Oase), in the realm of biology, and by the presence of original Neandertal inventions (personal ornaments made of animal teeth) in the cultural repertoire of Europe's earliest modern human societies.

Key Words: Neardental, Modern humans, Middle Paleolithicm and Upper Paleolithic.

$\left({ }^{*}\right)$ Este texto es el de una conferencia impartida en el Museo Municipal de Málaga, dia 14 de diciembre de 2005.

$\left(^{*}\right)$ Department of Archaeology and Anthropology. University of Bristol. 43 Woodland Road, Bristol BS8 1UU. United Kingdom. JoaoZilhao@bristol.ac.uk 


\section{INTRODUCCIÓN}

Hasta los años ochenta, fue consensual el punto de vista según el cual el paso del Paleolítico medio al superior y de los Neandertales al hombre moderno (en adelante, la Transición) había sido un proceso integrado, en el que los nuevos rasgos biológicos que terminaron haciéndose universales en la humanidad dicha "neantropiana" habrian emergido en poblaciones "paleoantropianas" con una cultura de tipo Paleolítico medio, en simultaneo con el desarrollo de un importante conjunto de innovaciones culturales. A estas últimas se las veía como formando un paquete, el "paquete Paleolítico superior", caracterizado por a) unas tecnologías líticas basadas en la producción de hojas, frecuentemente fabricadas sobre materiasprimas obtenidas a gran distancia de los yacimientos b) la emergencia de tradiciones regionales diferenciadas, interpretables, por lo menos en algún caso, como culturas en el sentido etnológico de la palabra c) la caza especializada de una restringida gama de presas, combinada con una base de subsistencia más amplia, incluyendo aves, peces y marisco d) un

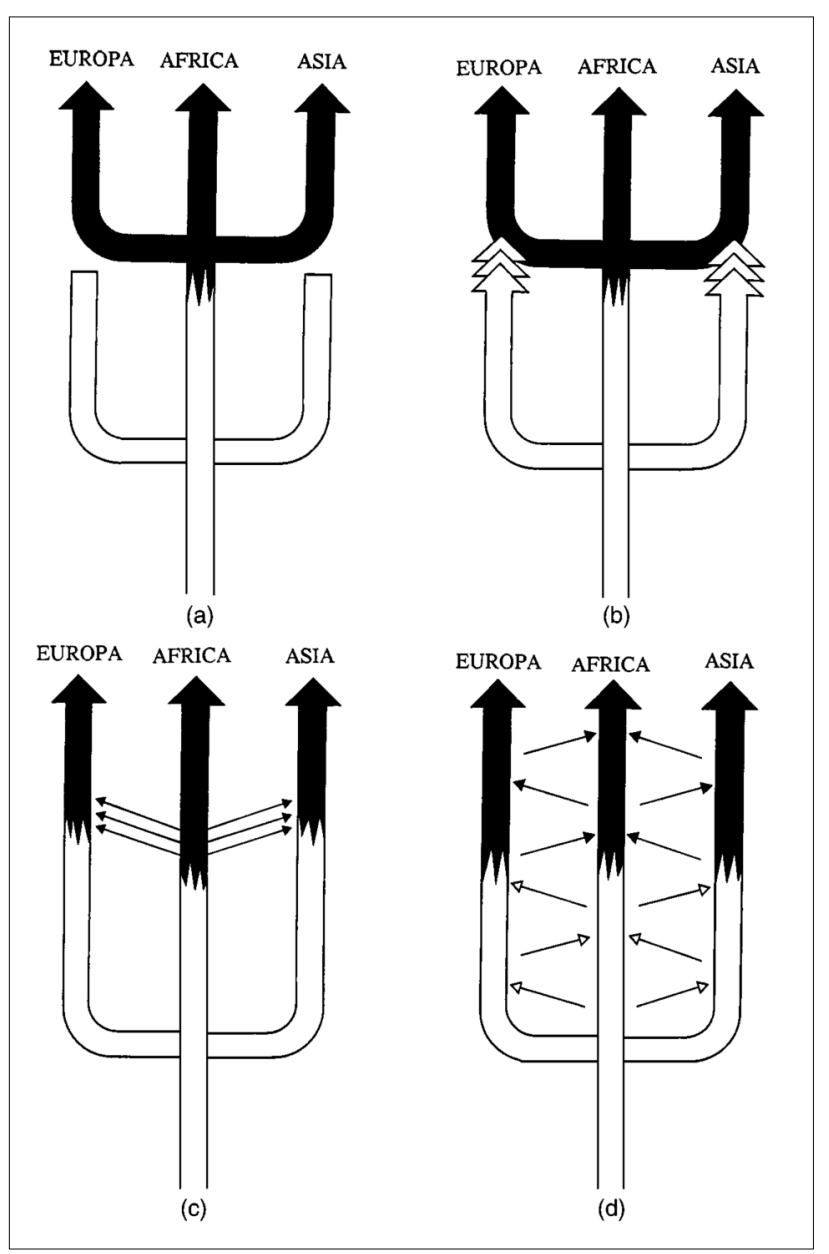

- Figura 1. Diferentes modelos para los origenes del hombre moderno (Stringer, 2002): (a) Out-of-Africa con substitución completa; (b) Out-of-Africa con hibridación y substitución; c) Asimilación; (d) Evolución multiregional. aumento del numero de yacimientos y de la densidad de restos en los depósitos arqueológicos, indicando efectivos demográficos superiores y grupos sociales más numerosos e) la mayor complejidad estructural de los campamentos residenciales f) la fabricación de útiles de hueso g) el uso de objetos de adorno y h) la producción de sofisticada arte figurativa (Brézillon, 1969; Mellars, 1973; White, 1982).

\section{ORIGENES DEL MODELO “OUT-OF-AFRICA”}

En el último cuartel del siglo veinte, esta visión del proceso fue cuestionada, en gran parte a raíz de los resultados obtenidos en el campo de la genética humana, en particular de los análisis de ADN mitocondrial de poblaciones actuales indicando un origen único, y reciente, en África, para toda la humanidad (Cann et al., 1987). A los datos genéticos se sumaron tres tipos de argumentos paleontológicos que también sugerían un origen reciente en África para los neantropianos de Europa: por una parte, el reconocimiento de que sus proporciones corporales eran características de poblaciones de clima tropical, en contraste muy evidente con las proporciones de tipo ártico de las poblaciones paleoantropianas del continente (los neandertales) (Trinkaus, 1981); por otra parte, el hecho de que los "proto-cromañones" de Skhul/Qafzeh databan del ultimo interglaciar y, por lo tanto, tenían la misma edad geológica que los cráneos completamente neantropianos de Omo-Kibish (Vandermeersch, 1981; Valladas et al., 1988); y finalmente, el hecho de que un proceso de evolución gradual de la condición neantropiana, a lo largo del Pleistoceno medio, se observaba en el registro fósil africano, pero no en el europeo (Bräuer, 1984; Stringer et al., 1984).

Tomados en su conjunto, estos desarrollos llevaban a una conclusión clara: a nivel biológico, la Transición había ocurrido en África mucho antes que en Europa, y los paleoantropianos representaban un linaje paralelo, sin salida, del árbol evolutivo de la humanidad. Esta conclusión se robusteció considerablemente cuando, a finales de los años noventa, Krings et al. (1997) extrajeron ADNmt antiguo de restos óseos del fósil de Neandertal.

Sin embargo, en la década que separa este trabajo del de Cann et al., no ocurrió ningún cambio comparable en el punto de vista paradigmático según el cual los procesos culturales subsumidos en la expresión "Paleolítico superior" estarian intima e inextricablemente conectados a cambios en la estructura del cerebro y en sus capacidades cognitivas ocurridos a lo largo del proceso general de neoantropización del esqueleto. No es por lo tanto de admirar que, en esos años, el consenso sobre la Transición haya evolucionado hacia la búsqueda de una síntesis que reconciliara los nuevos datos de la genética y de la paleontología con las definiciones arqueológicas tradicionales del Paleolítico medio y del Paleolítico superior. En 


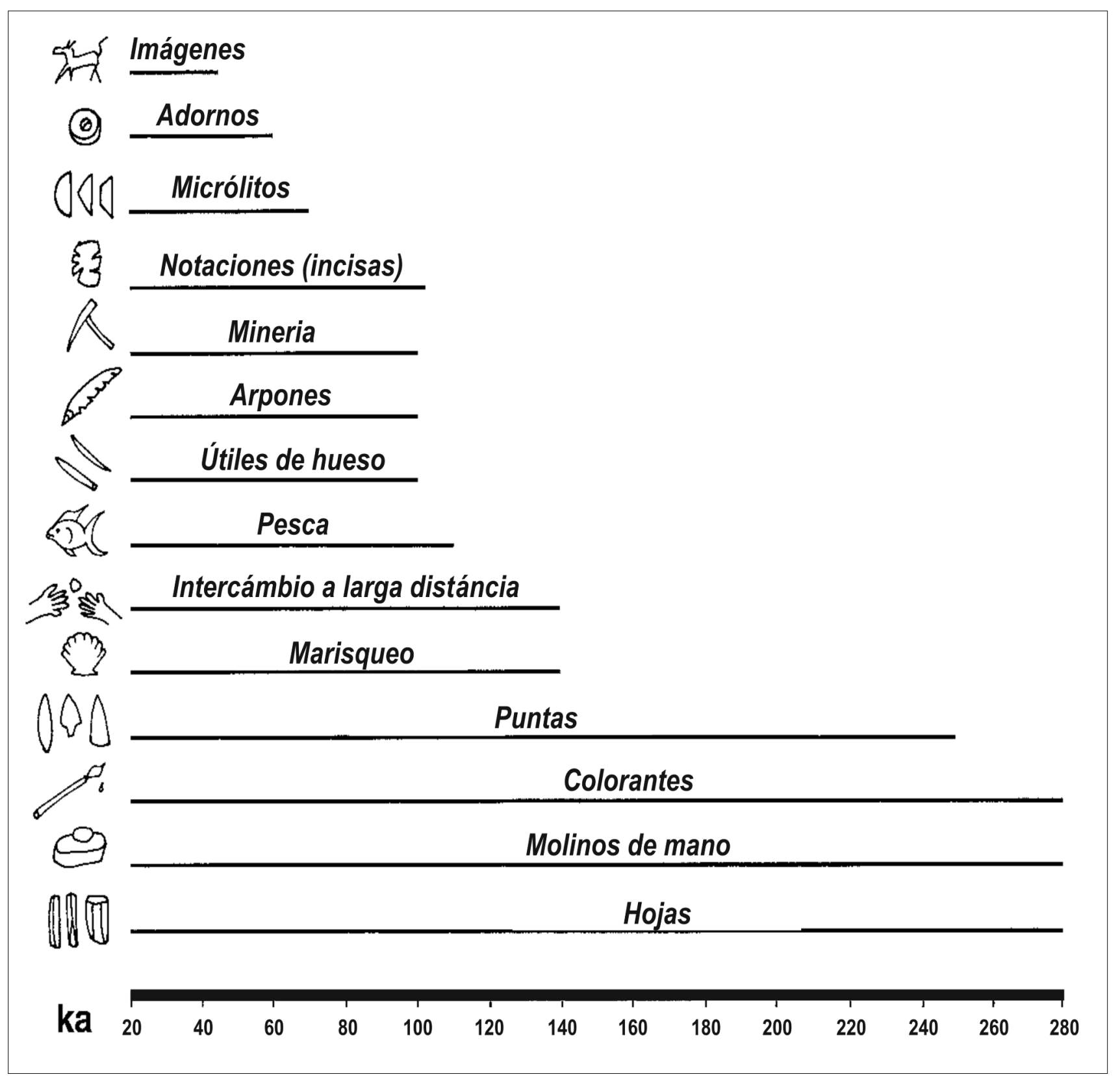

$\Delta$ Figura 2. Cronología de la emergencia de diferentes rasgos del comportamiento moderno en África (McBrearty y Brooks, 2000).

este nuevo marco, y para que no se rompiera la coherencia lógica interna del concepto de la Transición como un proceso biocultural integrado, el ámbito geográfico del fenómeno tenía que restringirse. Es así como, de forma "natural", terminó por cuajar el modelo de "Out-of-África con substitución completa", es decir, la idea según la cual la emergencia de la "modernidad", tanto a nivel biológico como a nivel cultural, había sido la culminación de un evento de especiación ocurrido en África, y su posterior extensión al resto del mundo producto de la expansión de esas gentes modernas dotadas de una cognición superior (fig. 1).

En lo que concierne a Europa, esta revisión del punto de vista sobre la Transición dominante en la posguerra conlleva- ba, por definición, que los paleoantropianos del continente no podían haber estado involucrados en el proceso: si no eran modernos en su anatomía tampoco podían serlo en sus rasgos comportamentales. Esta conclusión era coherente con la observación empírica de que las más antiguas manifestaciones incontrovertidas de arte figurativo en el continente databan de inicios del Paleolítico superior y provenían de niveles auriñacienses donde, aparentemente, se hallaban bien asociadas a restos osteológicos de poblaciones neantropianas. No puede sorprender, por lo tanto, que se haya planteado la hipótesis de que, en Europa, la historia de la Transición se resumiera muy sencillamente a la del proceso de extinción sin descendencia de una especie anatómica y comportalmente arcaica ("Ios nean- 
dertales"), como resultado de su inferioridad en la competencia con la especie anatómica y comportamentalmente moderna en expansión ("los humanos") (Stringer y Gamble, 1993).

\section{PROBLEMAS, SOLUCIONES Y CONTRADICCIONES}

Desde el principio, sin embargo, esta forma de reconciliar el registro arqueológico con un modelo de base esencialmente genética, como era el "Out-of-África con substitución completa", tuvo que enfrentarse a dos problemas importantes. En primer lugar, a lo largo de sus primeros 100.000 años, los restos arqueológicos dejados en África por los más antiguos humanos modernos no ofrecen ninguna evidencia de rasgos culturales de tipo Paleolítico superior. En segundo lugar, el Chatelperroniense, ampliamente reconocido como una entidad del Paleolítico superior (Leroi-Gourhan, 1964; Bordes, 1968) es una cultura de poblaciones neandertales, como se ha demostrado por el enterramiento de Saint-Césaire (Lévêque y Vandermeersch, 1980) y por los restos humanos de la Grotte du Renne (Hublin et al., 1996). Estos hechos chocaban directamente con el nuevo modelo de la Transición como un proceso biocultural totalmente integrado, obligando a la búsqueda de explicaciones satisfactorias para aquellas dos anomalías; no es por lo tanto un simple producto del azar que estos dos temas -los orígenes de la modernidad comportamental en África y el significado del Chatelperroniense- hayan ocupado un lugar central en los últimos diez años de investigación sobre los orígenes del hombre moderno.

En lo que concierne al continente africano, un primer intento de solución fue la hipótesis propuesta por Klein (2003, para una formulación reciente), según la cual el lenguaje y el pensamiento simbólico habrían aparecido sólo a raíz de una mutación genética muy reciente, ocurrida hace no más de unos 50.000 años; esto explicaría el gran salto cultural y demográfico que necesariamente supone la extraordinariamente rápida expansión del putativo grupo portador de la mutación original, primero por todo el continente africano y después hacia Eurasia. Sin embargo, como han comentado diferentes autores (Lahr y Foley, 1998; Shennan, 2001), está claro que esta solución no es coherente con los datos genéticos y arqueológicos, los cuales indican que el Out-ofAfrica de poblaciones modernas había empezado mucho antes de la fecha propuesta por Klein para la mutación cognitiva. Es así como surge entonces un punto de vista alternativo, que rápidamente se haria dominante: el de que la modernidad comportamental había evolucionado de forma gradual en el linaje africano que llevó de las poblaciones de tipo Kabwe a los hombres anatómicamente modernos de finales del Pleistoceno Medio (McBrearty y Brooks, 2000) (fig. 2).

Para que las cosas hubieran podido pasar así, sin embargo, el concepto de modernidad comportamental tenía que ser redefinido de forma ajustada a las características del registro arqueológico del Middle Stone Age (MSA) de África y, en particular, al hecho de que el arte figurativo sólo aparece en fase muy tardía de la secuencia continental. De hecho, aunque McBrearty y Brooks (2000) respalden una edad de más de 50.000 años para las losas pintadas de la cueva ApoIlo 11, el contexto estratigráfico y la datación del yacimiento (Wendt, 1974; Vogelsang, 1998) no permiten dudas: esas losas no pueden tener una antigüedad superior a unos 28.000 años (en la escala de tiempo del radiocarbono, es decir, unos 33.000 años de calendario). Pero sí es verdad que otros aspectos del registro ofrecen evidencias indirectas de pensamiento simbólico: por ejemplo, el patrón de distribución regionalizada de los diferentes tipos de puntas líticas del MSA (interpretado como manifestación de etnicidad), el uso de colorantes, o la presencia de objetos de adorno personal y de grabados abstractos en piezas de ocre de los niveles de la cultura Still Bay de la cueva de Blombos, fechados hacia unos 75.000 años antes del presente. Fue así como se generalizó la práctica de considerar el "comportamiento moderno" como sencillamente el "comportamiento plenamente simbólico de los sapiens", detectable en el registro arqueológico por la presencia de "artefactos o estructuras transmisoras de un mensaje exosomático claramente simbólico" (Henshilwood y Marean, 2003: 643-4).

En lo que concierne al continente europeo, el mantenimiento de la integridad lógica del modelo se intentó sugeriendo que el hallazgo de objetos simbólicos en el Chatelperroniense no tenía por que significar que tales objetos eran de producción neandertal. Se argumentó, por ejemplo, que, en la Grotte du Renne, el yacimiento clave donde mejor se documenta el uso de objetos de adorno por los Chatelperronienses, se trataba en realidad de objetos intrusivos, cuyo origen eran los niveles auriñacienses sobreyacientes (Taborin, 2002; White, 2002). Otro argumento fue el de que esos adornos podían representar piezas "carroñeadas" por Neandertales en yacimientos abandonados de poblaciones modernas auriñacienses coevas, evidencia de intercambio entre los dos grupos o, si realmente de producción neandertal, "imitación sin comprensión" de la artesanía simbólica de los auriñacienses (Stringer y Gamble, 1993; Hublin et al., 1996; Mellars, 1999). En cualquiera de sus formatos, estos argumentos compartían una negación de la capacidad de los Neandertales para el desarrollo independiente de culturas materiales simbólicas y, por esa vía, realizaban la conciliación de la realidad empírica del Chatelperroniense con el concepto de que la cognición sapiens y la modernidad comportamental eran un exclusivo del linaje africano.

A raíz de una serie de artículos publicados en la mudanza de siglo (d'Errico et al., 1998, 2003; Zilhão y d'Errico, 1999a, 1999b, 2000a, 2000b, 2003a, 2003b; Zilhão, 2001; d'Errico, 2003), quedó claro, sin embargo, que ninguna de las soluciones propuestas para el problema chatelperroniense 

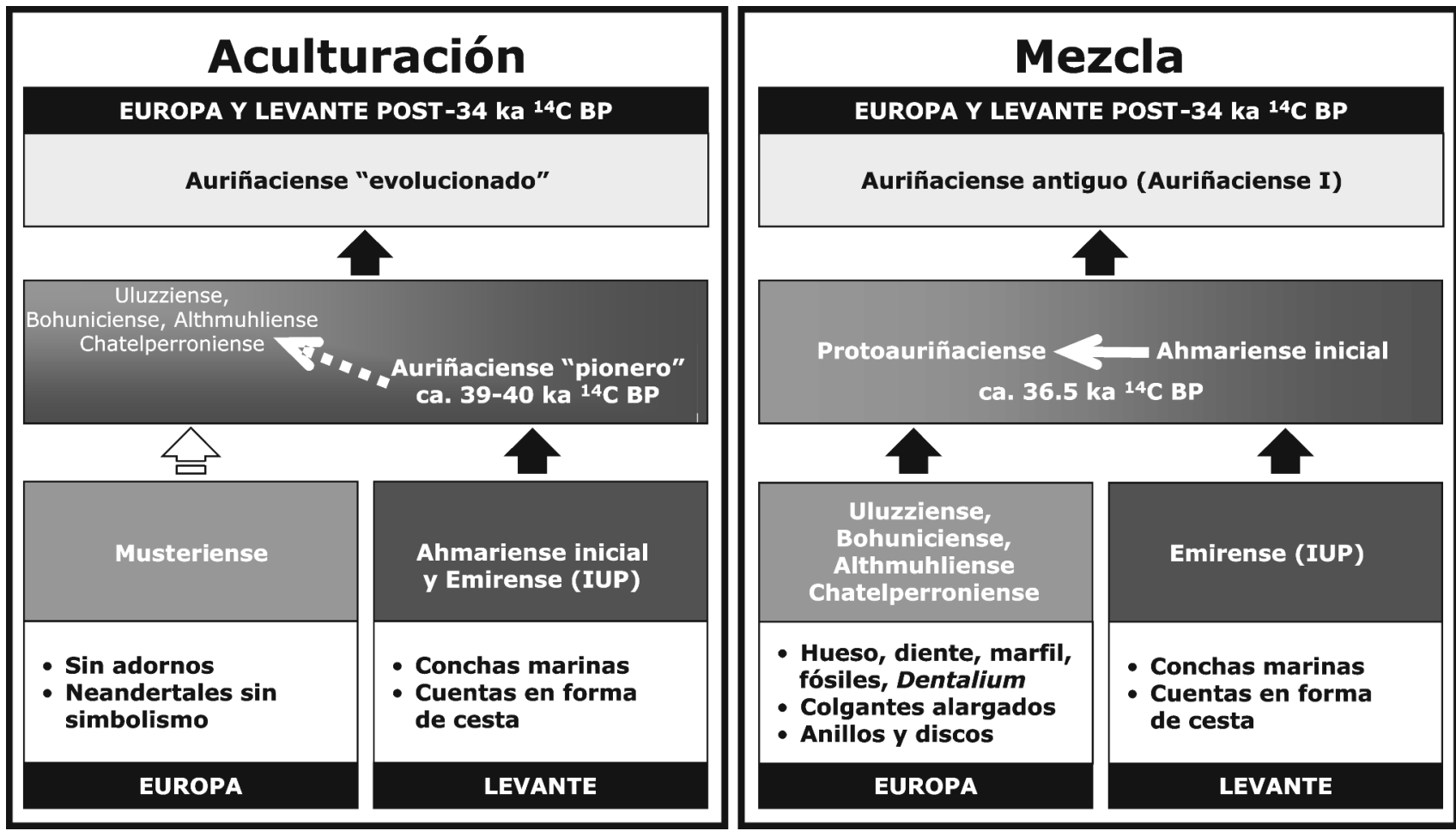

- Figura 3. Los dos tipos de modelos que se han propuesto para la significación del fenómeno protoauriñaciense, donde la lítica señala difusión a partir de Oriente Medio pero los adornos indican mezcla con las culturas neandertales autóctonas, que en la etapa precedente habían desarrollado de forma independiente su propia cultura material simbólica.

(imitación, tafonomia, intercambio, carroñeo) era compatible con las propiedades del registro empírico. El análisis de los datos de la Grotte du Renne mostró que la distribución vertical de los adornos a lo largo de la secuencia del yacimiento no permitía sostener la hipótesis de que se trataba de objetos intrusivos; por otra parte, la identificación de restos de producción demostró que los adornos y útiles de hueso decorados hallados en los niveles chatelperronienses no habian sido importados sino fabricados ahí mismo. Por lo tanto, o estos niveles representaban un desarrollo cultural autóctono e independiente de los Neandertales europeos, o "aculturación": a corta distancia, resultando en imitación (Mellars, 1999), o a larga distancia, resultando en reelaboración (Hublin, 2000) (Figura 3). La hipótesis de aculturación a corta distancia, sin embargo, no puede explicar las importantes diferencias que existen entre los útiles de hueso y los adornos del Chatelperroniense de la Grotte du Renne y sus posibles fuentes de inspiración auriñacienses, tanto en el tipo de soportes elegidos como en las técnicas de fabricación utilizadas. Y la hipótesis de aculturación a larga distancia (según la cual, además, seria ese el mecanismo por el que habrian llegado a Europa, procedentes de África o de Oriente Medio, todas las innovaciones culturales observadas a lo largo del Paleolítico medio, en particular el enterramiento de los muertos) conlleva una doble contradicción: por una parte, postula que la causa de la especiación de los Neandertales fue su prolongado aislamiento geográfico, impidiendo intercambio genético con las poblaciones africanas en proceso de evolución hacia la condición sapiens, pero al mismo tiempo propone una total integración de esos mismos Neandertales en redes de intercambio cultural a larga distancia incluyendo tanto a Europa como a África. Por otra parte, puesto que la difusión a larga distancia es necesariamente difusión de ideas y de conceptos, no apenas de objetos, es un mecanismo que sólo puede funcionar si el recipiente de las innovaciones posee las capacidades cognitivas para entenderlos cuya precisa ausencia la hipótesis se propone explicar.

\section{FÓSILES Y CULTURAS}

Aunque las hipótesis de aculturación todavía siguen de una forma o de otra vigentes en algunos sectores de la Paleoantropología, los más informados de entre los defensores del concepto según el cual los Neandertales no poseían una cognición y un comportamiento plenamente sapiens han comprendido que, de hecho, no les restaba más que una línea de argumentación: la de plantear que no sólo el Chatelperroniense sino también todas las otras industrias de Europa central y oriental contemporáneas, llamadas en general "transicionales", habian, en realidad, sido fabricadas por el hombre moderno, no por los Neandertales. Esta era ya, por supuesto, la opinión de François Bordes $(1972,1981)$, para quien el Neandertal de Saint-Césaire no representaba la gen- 


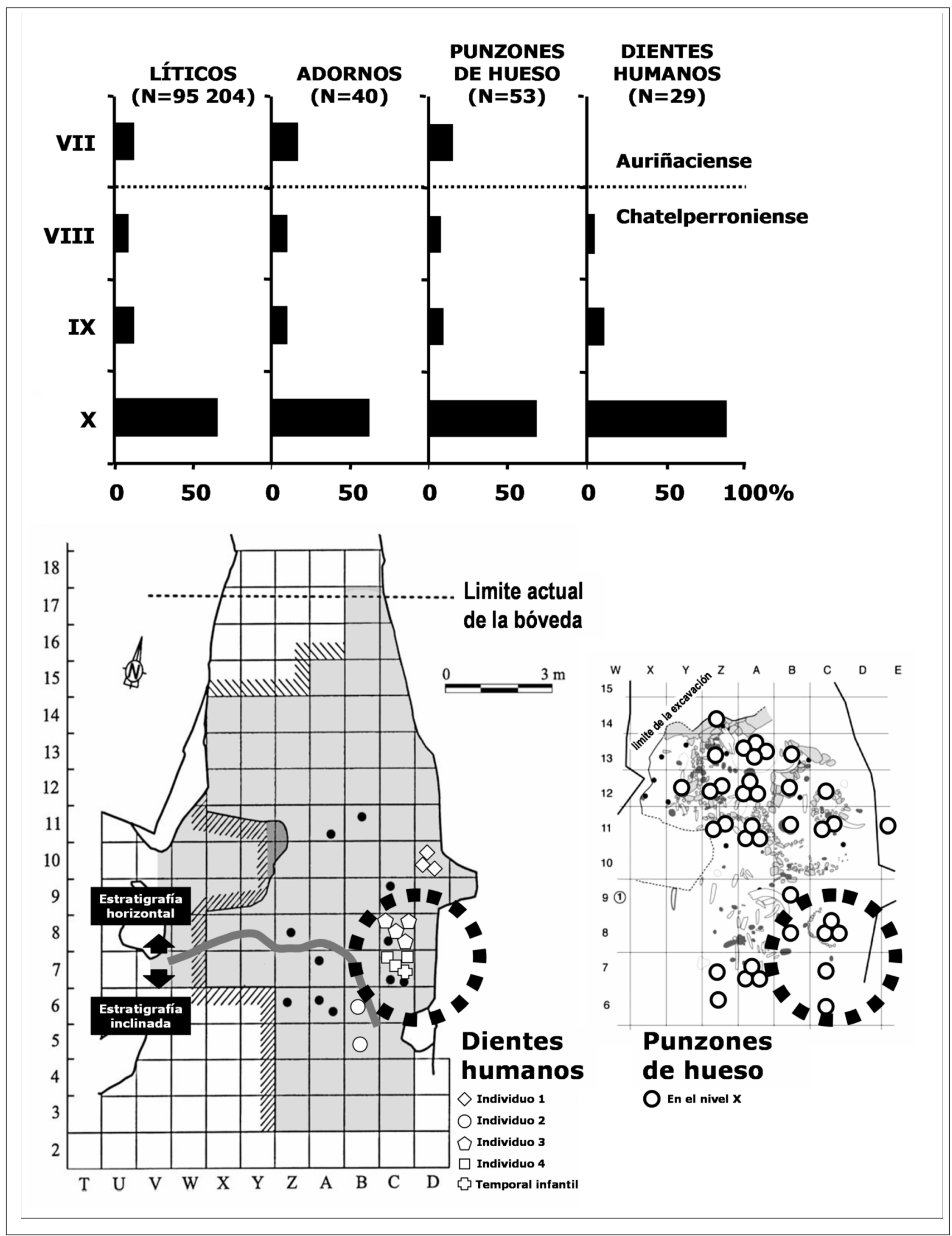

A Figura 4. Distribución vertical y horizontal de los restos arqueológicos y de los fósiles neandertales de la Grotte du Renne (Arcy-surCure, Francia) (d'Errico et al., 2003; Bailey y Hublin, 2006; Zilhão, 2006b). La gran mayoría de estos últimos viene del nivel X (tal como los adornos y los punzones), donde su distribución concentrada contra la pared Este de la cueva coincide con el área de proveniencia de un importante número de punzones de tipo chatelperroniense. 
te que había fabricado y utilizado los útiles de los niveles donde había sido enterrado sino sus victimas. Este tipo de razonamiento es el que más recientemente sigue Bar-Yosef (2006) al sugerir que los restos neandertales de los niveles chatelperronienses de la Grotte du Renne representan una intrusión a partir de los niveles musterienses infrayacentes, ya sea por procesos geológicos naturales o por mezcla de los dos niveles durante la excavación.

Para fortalecer la coherencia interna de estos argumentos, se ha sugerido también que las verdaderas raíces tecnológicas y tipológicas de estos tecnocomplejos del Paleolítico superior inicial no estaban en las culturas del Paleolítico medio de las diferentes regiones donde habían emergido sino en el Emirense (o IUP, Initial Upper Paleolithic) de Oriente Medio; el mejor ejemplo de esto sería el Bohunicense de Moravia y del sur de Polonia (Svoboda y Bar-Yosef, 2003). Bajo el supuesto de que el Emirense está asociado al hombre moderno (lo que es posible, incluso probable, pero queda por comprobar empíricamente), se planteó, por lo tanto, que el Bohuniciense (así como el Bachokiriense de Bulgaria y el Chatelperroniense de Francia) sería la manifestación en el registro arqueológico de la penetración del hombre moderno en Europa. Esa penetración, por lo tanto, habría precedido de forma significativa la emergencia del Auriñaciense, que hasta recientemente había sido unánimemente considerado por los defensores del "Out-of-África con substitución completa" como la representación del componente cultural del proceso de inmigración.

Sin embargo, en lo que concierne a la Grotte du Renne, la idea de que los restos neandertales de los niveles chatelperronienses habrian sido desplazados desde abajo es tan incompatible con la distribución vertical y horizontal de los hallazgos como lo era la idea de que los adornos de esos niveles habrian sido desplazados desde arriba (Zilhão, 2006b). (Figura 4). Todos los niveles chatelperronienses de la Grotte du Renne, desde el VIII a techo hasta el Xc a muro, han ofrecido dientes humanos (Bailey y Hublin, 2006). Aun descartando las veinte piezas de las cuadriculas 3 a 7 , donde la inclinación de la estratigrafía hace posible que hayan ocurrido perturbaciones y mezclas, las catorce restantes tienen la misma distribución: 1 es del nivel VIII, 1 del IX, 11 del Xb y 1 del Xc. Esta distribución es idéntica a la de los adornos y útiles de hueso, estando la concentración en el subnivel $\mathrm{Xb}$ conforme con el hecho de que también es ahi donde más abundantes son los materiales líticos en los que se basa el diagnostico industrial de estos niveles (Connet, 2002). Además, los conjuntos de piezas dentarias que, basándose en la edad y la morfología, se pueden atribuir a un mismo individuo, forman grupos con una dispersión muy reducida, es decir, lo opuesto a lo que sería de esperar si los niveles estuviesen muy perturbados. Finalmente, los dientes de los niveles VIII y IX, separados del nivel XI Musteriense por el espeso nivel $X(>50 \mathrm{~cm})$, están, tanto desde el punto de vista métrico como desde el punto de vista morfológico, dentro de la variación típica de los Neandertales y fuera de la de los modernos. A todo esto hay que añadir que, extrañamente, los niveles musterienses desde donde, supuestamente, este material habría sido desplazado, no contenían ni un solo resto humano, lo que es inconsistente con la hipótesis de ser ese el origen primario del material hallado en los niveles chatelperronienses.

Más allá de los datos proporcionados por la Grotte du Renne, hay que tener en cuenta que también la morfología de los dientes decíduos del nivel uluzziense de base de la Grotta del Cavallo, en Italia (el nivel E), es de afinidad neandertal. Son del mismo tamaño, presentan una morfología oclusal idéntica, y ostentan la condición taurodóntica, muy común en los molares decíduos de los Neandertales y hasta hoy desconocida en juveniles modernos (Churchill y Smith, 2000).

Nadie cuestiona que el Uluzziense tenga sus raíces en el Musteriense regional que le antecede (Palma di Cesnola, 1993; Mussi, 2001), y está aceptado desde Bordes que el origen del Chatelperroniense está en el MTA (Musteriense de Tradición Achelense) de Francia. Para Bordes, esta relación filética no era obstáculo a su idea de que el Paleolítico superior estaba asociado de forma exclusiva a poblaciones sapiens porque, para él, también el MTA había sido fabricado por ellas. Hoy en día, sin embargo, la continuidad entre las dos tradiciones culturales, aceptada de forma unánime antes del descubrimiento de Saint-Césaire (cf. Mellars, 1973), implica que la Transición en Francia, siendo un proceso totalmente autóctono, tiene que haber sido la consecuencia de desarrollos intrínsecos al mundo de los Neandertales.

La idea de que el Bohuniciense podría haber sido obra del hombre moderno se basa en tres tipos de razonamientos: 1) que la producción de hojas es desconocida en Moravia antes del Bohuniciense ; 2) que su cadena operativa es idéntica a la que se documenta en los niveles de base ( 1 y 2 ) del yacimiento de Boker Tachtit, en Israel; y 3) que, por lo tanto, el Bohuniciense representa la intrusión en la secuencia local de una tecnología proveniente de Oriente Medio, es decir, del lugar donde habría empezado el proceso de dispersión del hombre moderno hacia Europa. Estos razonamientos presuponen que la transición tecnológica observada en Boker Tachtit fue un acontecimiento único, y que la identificación de un conjunto lítico asimilable a una de las etapas de esa transición implica que haya sido fabricado por la población donde estaba en curso esa "mutación" tecnológica. Sin embargo, es evidente, por una parte, que una tecnología puede expandirse por difusión, sin migración y, por otra parte, hay que tener en cuenta que la naturaleza aparentemente intrusiva del Bohuniciense resulta sencillamente del hecho que, en Moravia, la secuencia crono-estratigráfica presenta un hiato de unos diez mil años entre el Micoquiense más reciente de la cueva de Klna y el más antiguo Bohuniciense. De hecho, los datos ofrecidos en los últimos años por los yacimientos de Piekarylla y Ksiecia 
Józefa, en el sur de Polonia (Sitlivy et al., 1999a, 1999b, 2004; Valladas et al., 2003), muestran, entre 50.000 y 40.000 años antes del presente (es decir, durante el periodo correspondiente al hiato de Moravia), un desarrollo local, a partir de una base tecnológica caracterizada por la producción Levallois de lascas, de métodos de reducción volumétrica de núcleos para extracción de hojas de tipo Paleolítico superior. Por lo tanto, siguiendo el principio de la parsimonia, no hace falta mirar hacia Oriente Medio para encontrar un origen para el Bohuniciense, una vez que existe una alternativa mejor, cronologica y geográficamente más cercana.

Al no haber restos humanos asociados al Bohuniciense, la cuestión de su autoría sigue sin solución definitiva, aunque la continuidad cultural con el Paleolítico medio regional indique que este más antiguo Paleolítico superior de Moravia está relacionado con los Neandertales, no con los modernos. Situación similar ocurre con el Bachokiriense de Bulgaria. Aunque Glen y Kaczanowski (1982) hayan sugerido, en su momento, que los dientes humanos de la cueva de Bacho Kiro presentaban rasgos neandertales, la revisión del material por Churchill y Smith (2000) concluyó que su tamaño, forma y morfología oclusal apuntaban más bien al hombre moderno. Esta conclusión, sin embargo, hacia referencia sólo a las piezas de los niveles auriñacienses, puesto que el único resto de los niveles bachokirienses era un fragmento mandibular con un diente deciduo sin rasgos diagnosticantes.

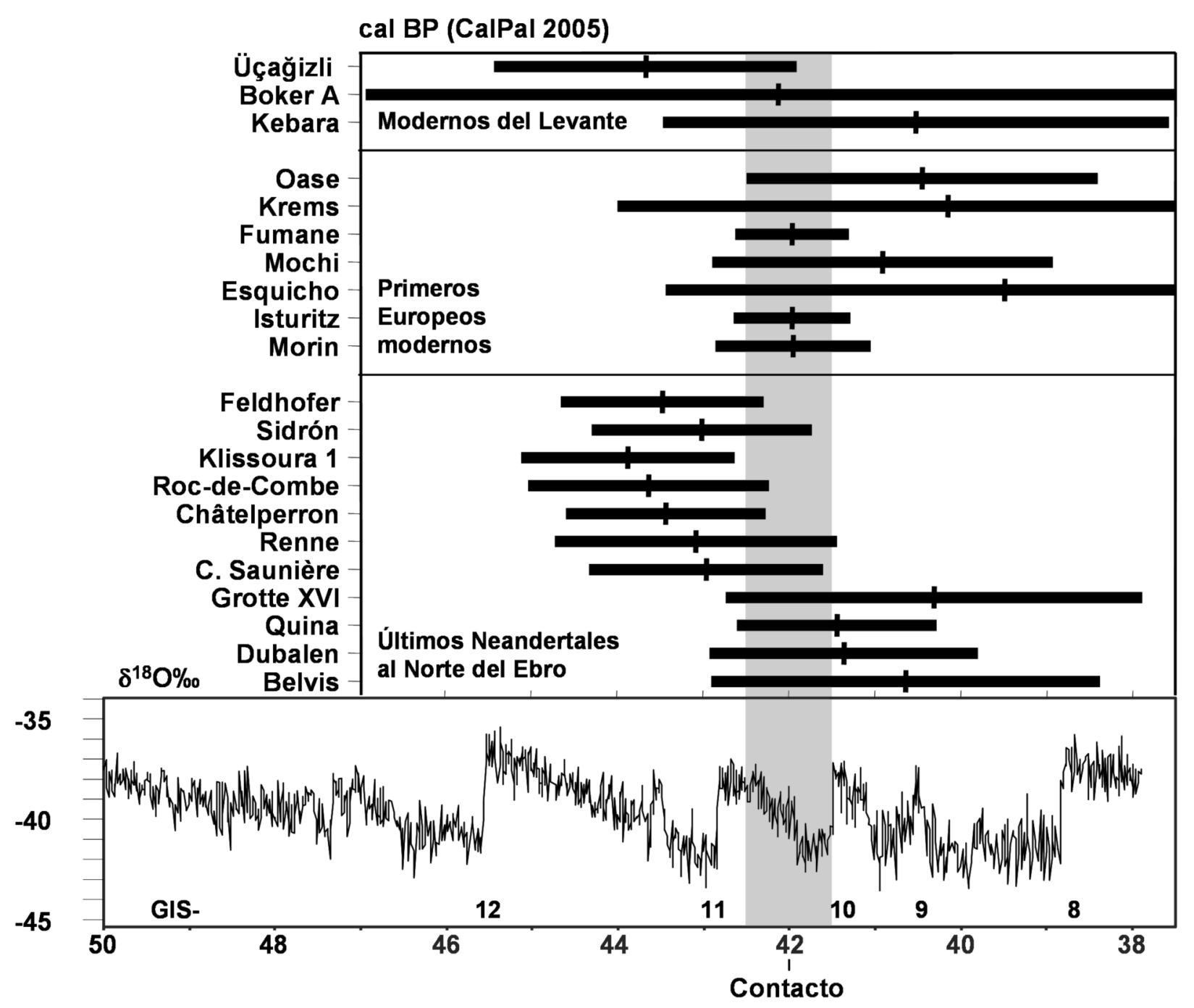

A FiguRA 5. Fechas radiocarbono calibradas (Weninger y Jöris, 2005) para los últimos Neandertales y los más antiguos humanos modernos de Europa y Oriente Medio (incluyendo las culturas arqueológicas a las que están asociados). El nivel más reciente del Emirense de Üçagizli constituye un terminus post quem para el Ahmariense inicial. La cola de resultados chatelperronienses más recientes refleja los problemas de decontaminación incompleta de las muestras de hueso, no una contemporaneidad de largo plazo con el Auriñaciense. El momento del contacto está situado hacia 42.000 años de calendario, y parece coincidir con un episodio climático templado (el interestadio 11 de la secuencia de los hielos de Gronelandia). 

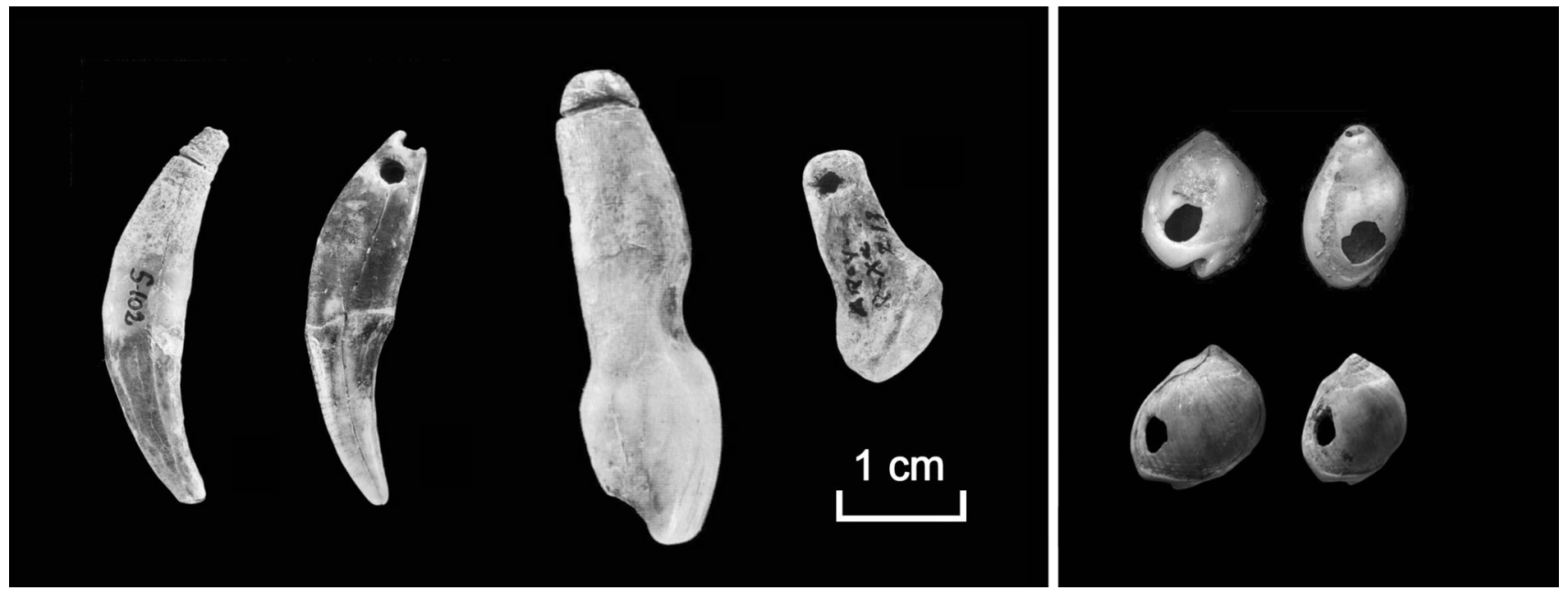

$\Delta$ Figura 6. El tipo de adornos característico del Chatelperroniense son los colgantes alargados sobre diente o hueso (a la izquierda; caninos de zorro, incisivo de bisonte y falange de reno, todos de la Grotte du Renne); el tipo de adornos característico de las culturas del hombre moderno en África y Oriente Medio antes de la inmigración a Europa son las cuentas en forma de cesta sobre conchas marinas (a la derecha; Nassarius gibbosula del Emirense de Üçaizli y Nassarius kraussianus del MSA de Blombos) (Baffier, 1999; Kuhn et al., 2001; d'Errico et al., 2005). Los dos tipos de adornos aparecen juntos en el Protoauriñaciense, sugeriendo una herencia cultural neandertal en relación con los procesos de mezcla biológica inferidos a partir de fósiles como los de Oase (Rumania).

\section{CONCLUSION}

De esta revisión de los datos sobre la asociación entre fósiles humanos y culturas arqueológicas resulta que, desde Bulgaria en el Este hasta Francia en el Oeste, el más antiguo Paleolítico superior de Europa es un fenómeno neandertal. Esta conclusión es apoyada por los datos cronométricos, los cuales sitúan la emergencia de todos estos tecnocomplejos hacia no menos de 40.000 años de radiocarbono antes del presente (es decir, unos 44.000 años de calendario), mientras que la edad de los restos de hombre moderno más antiguos de Europa, la mandíbula Oase 1 y el cráneo Oase 2 es de 35.000 años de radiocarbono antes del presente (es decir, unos 40.500 años de calendario) (Trinkaus et al., 2003; Trinkaus, 2005; Zilhão et al., 2007) (fig. 5). Llegados a este punto, las conclusiones son obligadas. Si utilizamos en Europa los mismos criterios aplicados en África para medir la emergencia del comportamiento moderno entre los hombres anatómicamente modernos de ese continente, vemos como la diversidad estilística y la repartición geográfica de las culturas, definidas sobre la base del utillaje lítico, las marcaciones abstractas, decorativas, en útiles de hueso (para las que un importante precedente es la decoración de cúpulas observada en la losa que tapaba la fosa sepulcral musteriense del niño La Ferrassie 6), y el uso de objetos de adorno (documentados no sólo en la Grotte du Renne sino también en niveles contemporáneos de Quinçay, Roche-au-Loup, Saint-Césaire, Trou Magrite, Ranis, Willendorf II y Bacho Kiro), sólo pueden interpretarse como prue- ba inequívoca de comportamiento moderno entre poblaciones que, desde el punto de visto anatómico, seguian siendo "arcaicas" (Zilhão, 2001, 2006a, 2006b, 2007).

Esta conclusión tiene dos importantes corolarios para el tema de la evolución humana en general: el primero es que, aunque necesariamente interrelacionados, los dominios de la anatomía y de la cultura han evolucionado de forma asincrónica y, por lo tanto, no es legítima la expectación de que, en nuestros orígenes, a cada especie paleontologicamente reconocida habrá correspondido un modelo de comportamiento exclusivo de ella; el segundo es que la adquisición del hardware necesario al comportamiento moderno es anterior a la diferenciación de los Neandertales, es decir, ese hardware existía ya entre los Homo heidelbergensis y posiblemente incluso entre los últimos Homo erectus/ergaster.

En lo que concierne al destino de los Neandertales, una vez empezado el proceso de inmigración hacia Europa de los modernos, hay todavía un tercer corolario: el de que es legítima la expectación de que el contacto haya dado origen a fenómenos de mezcla biológica y de intercambio cultural, como sugerido por los más recientes datos de la genética y de la paleontología humana (Templeton, 2005; Trinkaus, 2005; Zilhão, 2006a), y por la presencia en el Protoauriñaciense y en el Auriñaciense antiguo de tipos de ornamentos (dientes perforados y tubos de concha de Dentalium) que, siendo totalmente desconocidos en África y Oriente Medio antes del contacto, son, precisamente, los que caracterizan las culturas neandertales del Paleolítico superior inicial de Europa (Zilhão, 2006b, 2007) (fig. 6). 


\section{BIBLIOGRAFIA}

BAfFIER, D. (1999): Les derniers Néandertaliens. Le Châtelperronien, Paris, La maison des roches.

BAILEY, S. E. Y HUBLIN, J. J. (2006): Dental remains from the Grotte du Renne at Arcy-sur-Cure (Yonne). "Journal of Human Evolution" (in press).

BoRdES, F. (1968): Le Paléolithique dans le monde, Paris, Hachette.

BORDES, F. (1972): Du Paléolithique moyen au Paléolithique supérieur: continuité ou discontinuité?, in BORDES, F. (ed.) - "The origin of Homo sapiens", Paris, UNESCO, p. 211-217.

BORDES, F. (1981): Un néandertalien encombrant. "La Recherche», 12, p. 643-645.

BréżlLon, M. (1969): Dictionnaire de la Préhistoire, Paris, Larousse.

CAnn, R. L.; Stoneking, M. y WiLson, A. C. (1987): Mitochondrial DNA and human evolution. "Nature», 325, p. 31-36.

Churchill, S. E. Y SMith, F. H. (2000): Makers of the Early Aurignacian of Europe. "Yearbook of Physical Anthropology", 43, p. 61-115.

CONNET, N. (2002): Le Châtelperronien: Refléxions sur l'unité et l'identité techno-économique de l'industrie lithique. L'apport de l'analyse diachronique des industries lithiques des couches Châtelperroniennes de la grotte du Renne à Arcy-sur-Cure (Yonne). Ph. D. dissertation, University of Lille I.

D'ERrico, F. (2003): The Invisible Frontier. A Multiple Species Model for the Origin of Behavioral Modernity. "Evolutionary Anthropology", 12, p. 188-202.

D'Errico, F.; Zilhão, J.; Baffier, D.; Julien, M. y Pelegrin, J. (1998): Neanderthal Acculturation in Western Europe? A Critical Review of the Evidence and Its Interpretation. "Current Anthropology", 39, Supplement, p. S1-S44.

D'Errico, F.; Henshilwood, Ch.; Vanhaeren, M. y Van Niekerk, K. (2005): Nassarius kraussianus shell beads from Blombos Cave: evidence for symbolic behaviour in the Middle Stone Age. "Journal of Human Evolution", 48, p. 3-24

D'Errico, F.; Julien, M.; Liolios D.; Vanhaeren, M. y Baffier, D. (2003): Many awls in our argument. Bone tool manufacture and use in the Châtelperronian and Aurignacian levels of the Grotte du Renne at Arcysur-Cure, in Zilhão, J.; D'Errico, F. (eds.) - "The Chronology of the Aurignacian and of the Transitional Technocomplexes. Dating, Stratigraphies, Cultural Implications", Lisboa, Trabalhos de Arqueologia 33, Instituto Português de Arqueologia, p. 247-270.

GLE, E. Y KACZANOWSKI, K. (1982): Human Remains, in KozLowsKI, J. (1982) (ed.): Excavation in the Bacho Kiro cave (Bulgaria). Final Report, Warsaw, Polish Scientific Publishers, p. 75-79.

Henshilwood, C. y Marean, C. (2003): The Origin of Modern Human Behavior. Critique of the Models and Their Test Implications. "Current Anthropology", 44 (5), p. 627-651.

HUBLIN, J. J. (2000): Modern-nonmodern hominid interactions: A Mediterranean perspective, in BARR-YOSEF, O.; PILBEAN, D. (eds.): "The Geography of Neandertals and Modern Humans in Europe and the Greater Mediterranean", Cambridge, Peabody Museum Bulletin 8, p. 157-182.

Hublin, J. J.; SPOOR, F.; Braun, M.; Zonneveld, F. y Condemi, S. (1996): A late Neanderthal associated with Upper Palaeolithic artefacts. «Nature», 381, p. 224-226.

KLEIN, R. G. (2003): Whither the Neanderthals? «Science», 299, p. 15251527.

Krings, M.; Stone, A.; Schmitz, R. W.; Krainitzki, H.; Stoneking, M. y PäÄвo, S. (1997): Neandertal DNA Sequences and the Origin of Modern Humans. "Cell», 90, p. 19-30.

KuHn, S. L.; StIner, M. C.; REESE, D. S. y GÜLEC, E. (2001): Ornaments of the earliest Upper Paleolithic: New insights from the Levant. "Proceedings of the National Academy of Sciences USAm, 98 (13), p. 7641-7646.

LAHR, M. M. Y FOLEY, R. (1998): Towards a Theory of Modern Human Origins: Geography, Demography, and Diversity in Recent Human EvoIution. "Yearbook of Physical Anthropology», 41, p. 37-176.

Lerol-Gourhan, A. (1964): Les religions de la Préhistoire, Paris, Presses Universitaires de France.
LÉVÊOUE, F. Y VANDERMEERSCH B. (1980): Découverte de restes humains dan un niveau castelperronien à Saint-Césaire (Charente-Maritime). "Comptes rendus de l'Académie des Sciences de Paris», 291D, p. 187-189.

McBREARTY, S. Y BROOKS, A. (2000): The revolution that wasn't: a new interpretation of the origin of modern human behavior. "Journal of Human Evolution", 39, p. 453-563.

MELLARS, P. A. (1973): The character of the middle-upper paleolithic transition in south-west France, in RENFREW, C. (ed.) - "The Explanation of Cultural Change. Models in Prehistory", London, Duckworth, p. 255-276.

MelLaRS, P. A. (1999): In: The Neanderthal Problem Continued. "Current Anthropology", 40 (3), p. 341-350.

Mussı, M. (2001): Earliest Italy. An Overview of the Italian Paleolithic and Mesolithic, New York, Kluwer Academic.

Palma Di Cesnola, A. (1993): I/ Paleolitico superiore in Italia, Firenze, Garlatti e Razzai.

SHennan, S. (2001): Demography and Cultural Innovation: a Model and its Implications for the Emergence of Modern Human Culture. "Cambridge Archaeological Journal», 11 (1), p. 5-16.

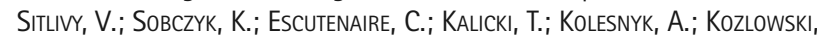
J.; Mercier, N.; TISnerat-Laborde, N.; Valladas, H. y ZiebA, A. (2004): Late Middle Paleolithic Complexes of Cracow Region, Poland, in "Actes du XIVème Congrès UISPP, Section 6, Le Paléolithique Supérieurn, BAR International Series 1240, 0xford, p. 305-317

Sitlivy, V.; SobCZYK, K.; KALICKI, T.; EsCUTENAIRE, C.; ZieBA, A. y KaCZOR, K. (1999a): The newPaleolithic Site of Ksiecia Józefa (Cracow, Poland) with Blade and Flake Reduction. "Préhistoire Européene», 15, p. 87-111.

SitLIVY, V.; SobCZYK, K.; MorawSKI, W.; ZIeBA, A. y EscutenaIRE, C. (1999b): Piekary lla Paleolithic Industries: Preliminary Results of a New Multidisciplinary Investigations. "Préhistoire Européene», 15, p. 45-64.

STRINGER, C. (2002): Modern human origins: progress and prospects. "Philosophical Transactions of the Royal Society London B», 357, p. 563-579.

StRINGeR, C. y GAMBLE, C. (1993): In Search of the Neanderthals, London, Thames and Hudson.

SVOBODA, J. y BAR-YOSEF, O. (eds.) (2003): Stránská skála. Origins of the Upper Paleolithic in the Brno Basin, Moravia, Czech Republic, Cambridge MA, American School of Prehistoric Research Bulletin 47.

TABORIN, Y. (2002): Les objets de parure et les curiosa, in SCHMIDER, B. (ed.): "L'Aurignacien de la grotte du Renne. Les fouilles d'André LeroiGourhan à Arcy-sur-Cure (Yonne)", Paris, Gallia Préhistoire Supplément XXXIV, p. 251-256.

Templeton, A. (2005): Haplotype Trees and Modern Human Origins. "Yearbook of Physical Anthropology", 48, p. 33-59.

TRINKAUS, E. (1981): Neanderthal limb proportions and cold adaptation in StRINGER, C. B. (ed.): "Aspects of Human Evolution», London, Taylor and Francis, p. 187-224.

TrinKaus, E. (2005): Early Modern Humans. "Annual Reviews of Anthropology", 34, p. 207-230.

Trinkaus, E.; Moldovan, O.; Milota, S.; Bîlgâr, A.; Sarcina, L; Athreya, S. Bailey, S. E.; Rodrigo, R.; Mircea, G.; Higham, Th.; Bronk Ramsey, C. H. Y PLICHT, J. v. d. (2003): An early modern human from the Pestera cu Oase, Romania. "Proceedings of the National Academy of Sciences USA», 100, p. 11231-11236.

Valladas, H.; Mercier, N.; Escutenaire, C.; Kalicki, T.; Kozlowski, J.; Sitlivy, V.; SOBCZYK, K.; ZIEBA, A. y VAn Vliet-LanOE, B. (2003): The late Middle Paleolithic blade technologies and the transition to the Upper Paleolithic in southern Poland: TL dating contribution. "Eurasian Prehistory", 1 (1), p. 57-82.

VALLAdAS, H.; ReYSS, J. L.; JORON, J. L.; VAlLAdAS, G.; BAR-YOSEF, O. Y VANDERMEERSCH, B. (1988): Thermoluminescence dating of Mousterian "Proto-Cro-Magnon" remains from Israel. "Nature», 331, p. 614-616.

VandermeersCH, B. (1981): Les Hommes Fossiles de Qafzeh (Israël), Paris, CNRS.

VogelSANG, R. (1998): Middle-Stone-Age-Fundstellen in Südwest-Namibia, Köln, África Praehistorica 11, Heinrich-Barth-Institut.

56 () UNED. Espacio, Tiempo y Forma. Serie I, Nueva época. Prehistoria y Arqueología, t. 1, 2008. 
WendT, W. E. (1974): "Art mobilier"aus der Apollo 11-Grotte in SüdwestAfrika. Die älteste datierten Kunstwerke Afrikas. «Acta praehistorica et archaeologican, 5, p. 1-42.

WenINGER, B. Y JöRIS, O. (2005): The Cologne Radiocarbon Calibration \& Paleoclimate Research Package (http://www.calpal.de).

WHITE, R. (1982): Rethinking the Middle/Upper Paleolithic Transition. "Current Anthropology", 23 (2), p. 169-192.

WHITE, R. (2002): Observations technologiques sur les objets de parure, in SCHMIDER, B. (ed.): «L'Aurignacien de la grotte du Renne. Les fouiIles d'André Leroi-Gourhan à Arcy-sur-Cure (Yonne)", Paris, Gallia Préhistoire Supplément XXXIV, p. 257-266.

ZILHÃO, J. (2001): Anatomically Archaic, Behaviorally Modern: The Last Neanderthals and Their Destiny, Amsterdam, Stichting Nederlands Museum voor Anthropologie en Praehistoriae.

ZıLHÃO, J. (2006a): Genes, Fossils and Culture. An Overview of the Evidence for Neandertal-Modern Human Interaction and Admixture. "Proceedings of the Prehistoric Society", 72 (en prensa).

ZıнHÃO, J. (2006b): Neandertals and Moderns Mixed, and It Matters. "Evolutionary Anthropology", 15, 183-195.

ZILHÃO, J. (2007): The emergence of ornaments and art: an archaeological perspective on the origins of behavioural "modernity". "Journal of Archaeological Research", 15, p. 1-54.

ZILHÃo, J. y D'ERRICO, F. (1999a): Reply, in The Neanderthal Problem Continued. "Current Anthropology», 40 (3), p. 355-364.
ZILHÄO, J. y D'ERRICO, F. (1999b): The chronology and taphonomy of the earliest Aurignacian and its implications for the understanding of Neanderthal extinction. "Journal of World Prehistory", 13 (1), p. $1-68$.

ZILHÃO, J. y D'ERRICO, F. (2000): La nouvelle "bataille aurignacienne». Une révision critique de la chronologie du Châtelperronien et de l'Aurignacien ancien. «L'Anthropologie», 104 (1), p. 17-50

ZIIHÃO, J. y D'ERRICO, F. (2003a): An Aurignacian "Garden of Eden" in southern Germany? An alternative interpretation of the Geissenklösterle and a critique of the Kulturpumpe model. "Paleo", 15, p. 69-86.

ZILHÃO, J. y D'ERRICO, F. (2003b): The chronology of the Aurignacian and Transitional technocomplexes. Where do we stand? in ZILHÃo, J.; D'ERRICO, F. (eds.) - "The Chronology of the Aurignacian and of the Transitional Technocomplexes. Dating, Stratigraphies, Cultural Implications", Lisboa, Trabalhos de Arqueologia 33, Instituto Português de Arqueologia, p. 313-348.

Zilhão, J.; Trinkaus, E.; Constantin, S.; Milota, S; Gherase, M.; SARcina, L.; Danciu, A.; Rougier, H.; QuilEs, J. y Rodrigo, R. (2007): The Pestera cu Oase people, Europe's earliest modern humans, in MeLLARS, P.; BoYLE, K.; BAR-YOSEF, O.; STRINGER, C. (eds.): «Rethinking the Human Revolution». New Beavioural and Biologhical Perspectives on the Origins and Disperal of Modern Humans", Cambridge, McDonald Institute for Archaeological Research (en prensa). 